Research Article

\title{
Study of Durability of Concrete with Fly Ash as Fine Aggregate under Alternative Interactions of Freeze-Thaw and Carbonation
}

\author{
Mingjie Mao $\mathbb{D}^{1,2}$, Dongsheng Zhang $\mathbb{D}^{1},{ }^{1}$ Qiuning Yang $\mathbb{D}^{1,},{ }^{1,2}$ and Wenbo Zhang ${ }^{1,2}$ \\ ${ }^{1}$ School of Civil and Hydraulic Engineering, Ningxia University, Yinchuan 750021, China \\ ${ }^{2}$ Arid Area Modern Agriculture Water Resources Efficient Utilization Ministry of Education Engineering Research Center, \\ Yinchuan 750021, China
}

Correspondence should be addressed to Qiuning Yang; yangqn@nxu.edu.cn

Received 11 January 2019; Revised 1 March 2019; Accepted 7 March 2019; Published 16 April 2019

Academic Editor: Faiz U.A. Shaikh

Copyright (C) 2019 Mingjie Mao et al. This is an open access article distributed under the Creative Commons Attribution License, which permits unrestricted use, distribution, and reproduction in any medium, provided the original work is properly cited.

To study the durability of concrete with fly ash as fine aggregate subjected to alternative attacks of freeze-thaw and carbonation, the appearance, mass loss, relative dynamic modulus of elasticity, relative compressive strength, and carbonation depth of the concrete are investigated using cyclic tests under single carbonation, single freeze-thaw, and alternation of freeze-thaw and carbonation. In addition, microstructural analysis techniques including scanning electron microscope and X-ray diffraction are adopted to reveal the deterioration mechanism of alternating freeze-thaw and carbonation. Results show that carbonation is beneficial for refining the pore structure and increasing concrete strength in the initial alternative cycle, which delays the damage from freeze-thaw cycles. Damage from freeze-thaw causes crack propagation in concrete, which leads to carbonation intensification. Compared with other test modes, concrete under alternative freeze-thaw and carbonation causes the greatest degree of deterioration during the initial freeze-thaw cycles. The carbonation depth under alternative freeze-thaw and carbonation is positively correlated with the carbonation time and the water-to-cement ratio. However, as the reactant is continuously consumed due to the expansion of crystalline ice and $\mathrm{CaCO}_{3}$, alternative cycles result in the appearance of many more new cracks in the concrete.

\section{Introduction}

Coal power plants worldwide produce a huge amount of waste fly ash, which not only causes environmental problems but is a threat to human health $[1,2]$. China is the largest producer of fly ash globally [3], and it produced approximately 600 million tons of fly ash in 2016. By the end of 2016, the waste fly ash has piled up to three billion tons. Due to its low comprehensive utilization rate, the fly ash has to be stored around the thermal power generation plants in a concentrated or scattered way, which not only occupies a lot of land but also results in certain pollution to the surrounding soil, water, and air. Therefore, it is necessary to develop effective technologies for better utilization of fly ash onsite in the construction field.
A considerable amount of research has been conducted in recent decades on the use of fly ash in cement concrete technology [4]. Fly ash is a by-product of industrial production, and some positive progress has been made in using it to solve sustainable construction challenges [5]. For example, during the period 2010-2012, its use in construction applications was approximately 55\%, and it is now considered to be a commercial product that is supplied in bulk. However, the positive function of fly ash is limited when used as a replacement material for cement as its strength develops slower than the cement [6]. Therefore, AIJ [7] proposed the use of fly ash as a partial replacement for fine aggregate. Part of fly ash acts as a cementitious material and has a microaggregate effect, while the rest provides a volcanic ash effect, which is attributed to the presence of $\mathrm{SiO}_{2}$ 
and $\mathrm{Al}_{2} \mathrm{O}_{3}$. It reacts with calcium hydroxide during cement hydration to form additional calcium silicate hydrate (CSH) and calcium aluminate hydrate $(\mathrm{CAH})$, which effectively forms a density matrix and results in a higher strength material $[5,8,9]$. As such, the early strength of concrete with fine aggregate that is partially replaced by fly ash is superior to that of concrete with fly ash in place of cement [10-13].

Environmental problems are increasing with respect to pressures from the rising global population, and climaterelated changes are having a detrimental effect on concrete structures and affecting their durability. In cold regions, concrete structures are not only subjected to freeze-thaw damage, but they also suffer from erosion by atmospheric carbon dioxide $\left(\mathrm{CO}_{2}\right)$; these effects cause structural damage with respect to freeze-thaw cycles and the carbonation of concrete, respectively, thereby resulting in complex actions that affect the durability of concrete structures in cold regions [14]. Kuosa et al. [15] suggested that an assessment of freeze-thaw and carbonation effects should be conducted in a laboratory to accurately simulate natural conditions. It is thus considered necessary to investigate the deterioration mechanism of structural concrete under freeze-thaw and carbonation impacts, both individually and alternately, and to compare their differences.

This study employed multiple cyclic tests to systematically investigate the impact of freeze-thaw cycling and carbonation on the durability of concrete in which fly ash was used as the fine aggregate. Data analysis was conducted to evaluate the concrete's characteristics (including appearance, mass, relative dynamic elastic modulus, relative compressive strength, and carbonation depth). The deterioration mechanism of concrete under the alternating action of freeze-thaw and carbonation was further investigated using microstructural analysis techniques such as scanning electron microscope (SEM) and X-ray diffraction (XRD) analysis. This study provides a fundamental basis for further investigating the durability of concrete with fly ash as a fine aggregate when used in complex environments. In addition, this study provides a theoretical basis for the time and quality management of concrete construction.

\section{Materials and Experiments}

2.1. Raw Materials. Table 1 shows the chemical compositions of $42.5 \mathrm{R}$ ordinary Portland cement and Class III fly ash $\left(2.058 \mathrm{~g} / \mathrm{cm}^{3}\right)$, which were obtained using the X-ray fluorescence spectrometer. The physical properties of cement and fly ash are shown in Table 2.

The coarse aggregate used was crushed stone with a continuous gradation and particle diameters of $5-31.5 \mathrm{~mm}$, and it included $0.6 \%$ mud. The crushing index was $10.2 \%$, and needle particles were $9.7 \%$. The fine aggregate was natural river sand with a density of $2600 \mathrm{~kg} / \mathrm{m}^{3}$ and a fineness modulus of 2.71 (medium sand), and it also comprised $1.27 \%$ water and $0.43 \%$ mud. Tap water and three triterpenoid saponins (powder) were used. A polycarboxylic acid superplasticizer that was suitable for fly ash fine aggregate concrete was used to ensure a desirable slump value.
2.2. Mixture Proportion. This test mainly explored the durability of concrete with fly ash as fine aggregate when subjected to alternative loading of freeze-thaw and carbonation. To meet the performance requirements of the concrete, the water-to-cement ratio of concrete was determined as $0.36,0.42$, and 0.48 , according to the "Technical Specification for the Application of Fly Ash Concrete" (GB/ T50146-2014) [16] and by considering the characteristics of fly ash. The equivalent volume replacement rate of fly ash was $15 \%$. Table 3 shows three specimens with different mixture proportions. Formula (1) represents the replacement of $15 \%$ fine aggregate with an equal volume of fly ash:

$$
M_{\mathrm{FA}}=\frac{M_{\mathrm{S}} \cdot 15 \% \cdot \rho_{\mathrm{FA}}}{\rho_{\mathrm{S}}},
$$

where $\rho_{\mathrm{S}}$ and $\rho_{\mathrm{FA}}$ are the density of fine aggregate and fly ash, respectively, and MS and MFA are the unit consumption of fine aggregate and fly ash, respectively.

2.3. Preparation of Specimens. The three concrete specimens were prepared according to the mixture proportions shown in Table 3. The test specimen was a prism with a size of $100 \mathrm{~mm} \times 100 \mathrm{~mm} \times 400 \mathrm{~mm}$, and the cube was used to control specimen strength that measured $100 \mathrm{~mm} \times 100 \mathrm{~mm}$ $\times 100 \mathrm{~mm}$. The specimen was formed under vibration on a concrete vibration table, and the mold was removed $24 \mathrm{~h}$ after the specimen was fabricated and then placed in a standard curing room (at a temperature of $20 \pm 2^{\circ} \mathrm{C}$ and relative humidity greater than $95 \%$ ) for 56 days prior to testing.

2.4. Experimental Design. According to data of the China Meteorological Administration (CMA), an average number of 6.2 equivalent freeze-thaw (F-T) cycles occur annually in northwest and northeast China $[17,18]$. In this study, the service life of concrete with fly ash as fine aggregate is assumed to be 30 years. Reasonable times of fast F-T cycles in the indoor test were $30 \times 6.2=186$. For the carbonation time, the natural $\mathrm{CO}_{2}$ concentration was $0.039 \%$, and a value of $20 \%$ was used in this study in the accelerated carbonation test chamber. Therefore, the accelerated carbonation test per day was equivalent to $20 \% / 0.039 \% / 365=1.56$ natural carbonation per year. The days of accelerated carbonation in the experiment were $30 / 1.56=19.23$. This study thus used $0-200$ times for F-T cycles and 0-20 days for the carbonation time.

Freeze-thaw alternations and carbonation occur in autumn-winter and winter-spring. As the mechanisms involved in freeze-thaw and carbonation are different, yielding concrete structures are various. Generally speaking, carbonation makes a structure denser, while freeze-thaw makes it looser; therefore, freeze-thaw or carbonation will affect the interaction results of the two factors on the concrete, and to investigate this, the test was divided into four different modes, as shown in Table 4. The abbreviations, FC, CF, F, and $\mathrm{C}$, in Table 4 represent these different modes: alternative freeze-thaw and carbonation (FC), alternative carbonation and freeze-thaw (CF), single freeze-thaw (F), and single carbonation $(\mathrm{C})$. 
TABLE 1: Chemical composition of cement and fly ash.

\begin{tabular}{lccccccccc}
\hline Oxide & $\mathrm{SiO}_{2}$ & $\mathrm{Al}_{2} \mathrm{O}_{3}$ & $\mathrm{CaO}$ & $\mathrm{Fe}_{2} \mathrm{O}_{3}$ & $\mathrm{MgO}$ & $\mathrm{SO}_{3}$ & $\mathrm{P}_{2} \mathrm{O}_{5}$ & $\mathrm{Na}_{2} \mathrm{O}$ & $\mathrm{K}_{2} \mathrm{O}$ \\
\hline Cement & 22.46 & 7.60 & 57.15 & 5.00 & 1.54 & 2.96 & 0.105 & 0.31 \\
Fly ash & 50.35 & 29.65 & 5.85 & 6.61 & 1.83 & 1.72 & 1.13 & 0.87 & 1.42 \\
\hline
\end{tabular}

TABle 2: Physical composition of cement and fly ash.

\begin{tabular}{lcc}
\hline Properties & Cement & Fly ash \\
\hline Fineness (\% retained in $80 \mu \mathrm{m})$ & 1.6 & 34.3 \\
Water demanded $(\%)$ & - & 97 \\
Loss on ignition (\%) & 1.4 & 5.7 \\
\hline
\end{tabular}

\subsection{Experimental Methods}

2.5.1. Freeze-Thaw Test. A rapid freeze-thaw method was employed in this study [19]. Concrete specimens were immersed in water $\left(20 \pm 2^{\circ} \mathrm{C}\right)$ for four days prior to the test to ensure they were water saturated. The specimens are dried by removing water from the surface. The mass and dynamic modulus of elasticity were measured, and specimens were placed in a freeze-thaw chamber that had an interior temperature between $-20^{\circ} \mathrm{C}$ and $20^{\circ} \mathrm{C}$. The temperature of the concrete's centre was controlled in the range of $(-18 \pm 2)^{\circ} \mathrm{C}$ and $(5 \pm 2)^{\circ} \mathrm{C}$, and the switching time between freezing and thawing did not exceed $10 \mathrm{~min}$. Water was employed as the test liquid [20,21]. When the number of freeze-thaw cycles reached a multiple of 25 , the above procedure was repeated, and the mass and dynamic modulus of elasticity were measured. The specimens were then turned over and placed back into the freeze-thaw chamber to minimize the temperature difference between the upper and lower surfaces. When the number of freezethaw cycles reached a multiple of 50, the strength of the group of specimens was measured. Figure 1 shows the test equipment employed.

2.5.2. Carbonation Test. A rapid carbonation test method was used in this study [19]. Specimens were firstly placed in an oven with an interior temperature of $60^{\circ} \mathrm{C}$ for two days, and the five sides of each specimen (not the top) were then sealed with paraffin. The specimens were subsequently placed in a carbonation chamber, with a space of more than $50 \mathrm{~mm}$ between each specimen. The interior of the chamber was controlled with a $\mathrm{CO}_{2}$ concentration of $20 \pm 3 \%$, temperature of $20 \pm 2^{\circ} \mathrm{C}$, and relative humidity of $70 \pm 5 \%$. Figure 2 shows the carbonation chamber used to conduct the concrete carbonation procedure. The carbonation depth and compressive strength were measured at $5 \mathrm{~d}, 10 \mathrm{~d}, 15 \mathrm{~d}$, and $20 \mathrm{~d}$.

2.5.3. Compressive Strength. According to the Standard for Testing Methods of Mechanical Properties of Ordinary Concrete (GB/T 50081-2002) [22], compressive strength tests were conducted on the concrete at a loading rate of $0.5 \mathrm{MPa} / \mathrm{s}$. Three blocks of each kind of the concrete specimen were tested, and the average from three compressive strength values was calculated.
2.5.4. Scanning Electron Microscope (SEM). Microscopic scanning analysis of A2 specimens before and after the fourth alternative cycle was carried using a JSM-7500F scanning electron microscope.

2.5.5. X-Ray Diffraction (XRD). The A2 specimen was further analyzed using X-ray diffraction (XRD) before and after the fourth alternative cycle. XRD was conducted on the dried concrete powder using a German Bruker D8 advance equipped with a graphite monochromator and copper anode. The step size employed in this study was $0.02^{\circ}$ at $1 \mathrm{~s} \mathrm{per}$ step in a $2 \theta$ range between $3-85^{\circ}$.

\section{Results and Discussion}

3.1. Analysis of Concrete Appearance. Following the cyclic freeze-thaw test, which was conducted on the concrete with fly ash as fine aggregate, microcracks were observed on its surface, and the amount of microcracks increased with an increase in the number of freeze-thaw cycles. In addition, the surface of the concrete became loose and parts peeled off. During the freeze-thaw cycling process, water in the pores and capillaries of the concrete turned into ice, and under the effect of swelling pressure, more water flowed to nearby capillaries. The movement of the water generated water pressure, and the liquid in the capillaries was actually a soluble salt. Clean water was separated during this process, which resulted in an increased concentration of the solution within the capillaries, which further yielded seepage pressure $[23,24]$. Therefore, under the joint effect of both water and seepage pressure, cracks developed in the concrete and it eventually deteriorated.

Figure 3 shows the changes in the appearance of specimens in Group A2 during freeze-thaw cycles. It can be seen that the concrete is initially intact (Figure 3(a)), but with an increasing number of freeze-thaw cycles, a small amount of pitting is observed on the concrete's surface (Figure 3(b)). As the cementing materials run off the concrete's surface, the pittings increase in size and number, and the fine aggregates on the surface are exposed and gradually peel off (Figure $3(\mathrm{c})$ ). The aggregates fall off layer by layer until the coarse aggregates are exposed (Figures 3(d) and 3(e)). Figures $3(\mathrm{e})-3(\mathrm{~g})$ show that more concrete damage occurs when it is subjected to alternative attacks of freeze-thaw and carbonation rather than when single freeze-thaw cycles employed.

3.2. Mass Loss Analysis. Figure 4 presents the mass loss rates of specimens in Groups A1, A2, and A3 with different testing modes, and the following is evident: first, the mass loss rate curves of all concrete specimens have the same trend, i.e., the 
TABle 3: Three specimens with different mixture proportions in concrete $\left(\right.$ per $\mathrm{m}^{3}$ ).

\begin{tabular}{lcccccccc}
\hline $\begin{array}{l}\text { Batch } \\
\text { no. }\end{array}$ & $\begin{array}{c}\text { Water-to- } \\
\text { cement } \\
\text { ratio }\end{array}$ & $\begin{array}{c}\text { Water } \\
\left(\mathrm{kg} / \mathrm{m}^{3}\right)\end{array}$ & $\begin{array}{c}\text { Cement } \\
\left(\mathrm{kg} / \mathrm{m}^{3}\right)\end{array}$ & $\begin{array}{c}\text { Fly ash } \\
\left(\mathrm{kg} / \mathrm{m}^{3}\right)\end{array}$ & $\begin{array}{c}\text { Sand } \\
\left(\mathrm{kg} / \mathrm{m}^{3}\right)\end{array}$ & $\begin{array}{c}\text { Gravel } \\
\left(\mathrm{kg} / \mathrm{m}^{3}\right)\end{array}$ & $\begin{array}{c}\text { Superplasticizer } \\
\text { agent (\%) }\end{array}$ & $\begin{array}{c}\text { Air- } \\
\text { entraining } \\
\text { agent }(\%)\end{array}$ \\
\hline A1 & 0.36 & 185 & 514 & 80 & 569 & 1003 & 2.0 & 0.014 \\
A2 & 0.42 & 185 & 440 & 85 & 608 & 1030 & 1.8 & 0.020 \\
A3 & 0.48 & 185 & 385 & 90 & 643 & 1045 & 1.5 & 0.020 \\
\hline
\end{tabular}

TABLE 4: Test grouping.

\begin{tabular}{lccc}
\hline Test mode & Test program & \\
\hline Freeze-thaw and carbonation (FC) & $\begin{array}{c}\text { Freeze-thaw cycle } 50 \text { times } \\
\text { Carbonation and freeze-thaw (CF) }\end{array}$ & $\begin{array}{c}\text { Carbonation } \\
\text { environment } 5 \mathrm{~d}\end{array}$ & $\begin{array}{c}\text { Tap water, immersing for } 4 \mathrm{~d} \\
\text { environment } 5 \mathrm{~d}\end{array}$ \\
$\begin{array}{l}\text { Single freeze-thaw (F) } \\
\text { Single carbonation (C) }\end{array}$ & $\begin{array}{c}\text { Freeze-thaw cycle } 50 \text { times } \\
\text { Carbonation environment for } 5 \mathrm{~d}\end{array}$ \\
\hline
\end{tabular}

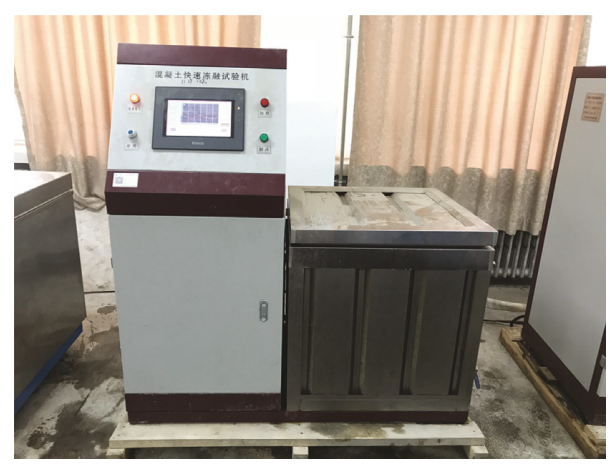

FIgURE 1: Equipment used to conduct rapid freeze-thaw test.

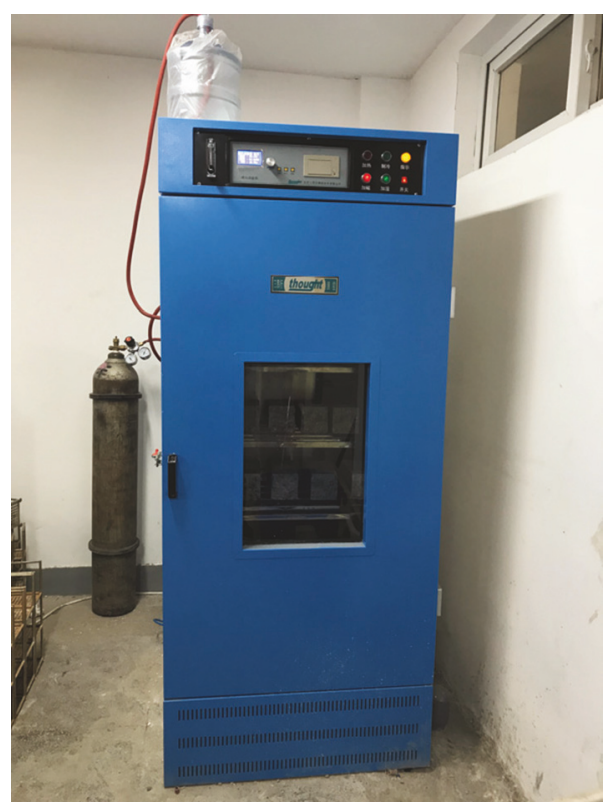

FIgURE 2: Rapid carbonation test chamber. 


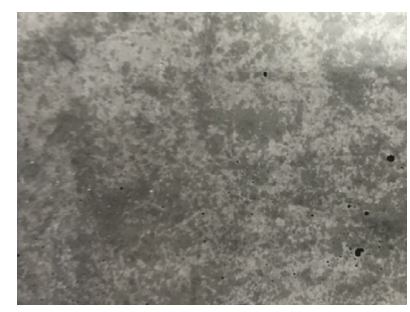

(a)

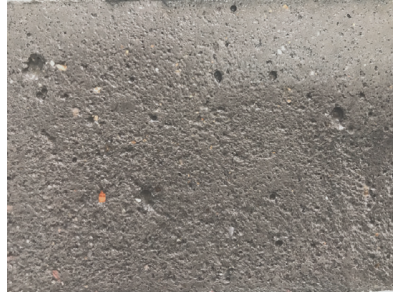

(b)

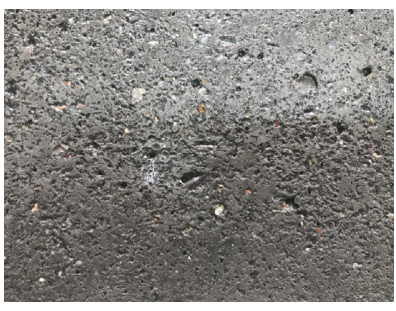

(c)

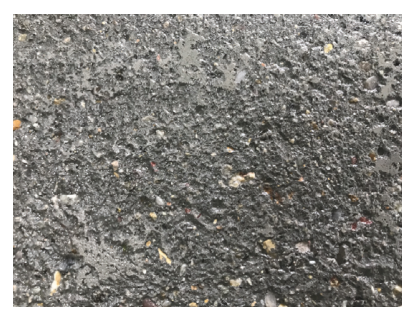

(d)

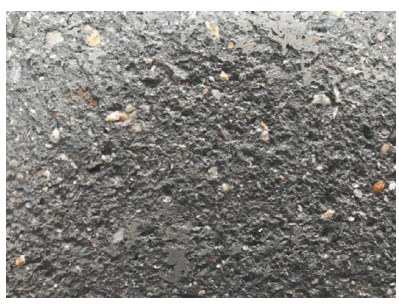

(e)

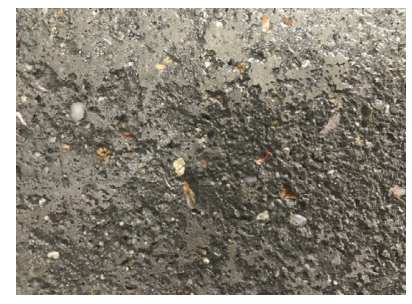

(f)

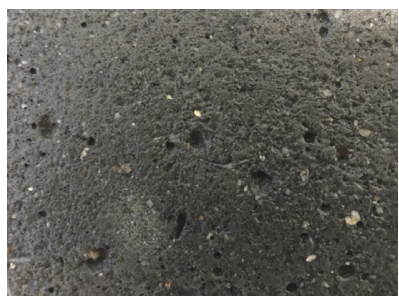

(g)

Figure 3: A2 surface damage: (a) A2-FC 0 cycles; (b) A2-FC 50 cycles; (c) A2-FC 100 cycles; (d) A2-FC 150 cycles; (e) A2-FC 200 cycles; (f) A2-CF 200 cycles; (g) A2-F 200 cycles.

mass loss rate increases with an increase in the number of freeze-thaw cycles. This occurs because the free water in the concrete freezes and expands, cohesion between aggregates drops, and erosion occurs to the concrete and causes damage. With alternations in temperature (rises and falls), everchanging tension and compression stress occurs in the concrete, which causes the concrete specimens to undergo fatigue failure. As a result, the specimens are destroyed from the surface to the internal structure, and the damage increases with an increase in the cycling numbers. Second, with an increase in the water-to-cement ratio, the mass loss rate of concrete specimens is higher. Concrete with a high watercement ratio generally contains a higher volume of pore water. Such pore water is typically partially consumed over time during the hydration process, and some is lost when the concrete dries. This creates voids [25] and results in a higher mass loss rate under freeze-thaw cycling [26, 27]. Third, compared with ordinary concrete [28], the mass loss rate of concrete with fly ash as a fine aggregate is always less than $5 \%$ with less than 200 times of freeze-thaw cycles, which is far less than that of ordinary concrete. The reason for this is that fly ash is a pozzolanic material, and the active ingredients within it $\mathrm{SiO}_{2}$ and $\mathrm{Al}_{2} \mathrm{O}_{3}$ react with the hydration products of cement and lime to produce hydrated calcium silicate and hydrated calcium aluminate, which further react with gypsum to produce hydrated calcium aluminate sulfate. This significantly reduces the porosity of the concrete and changes the pore structure. Consequently, cohesion between the concrete constitutes is improved, the concrete becomes more and more compact, and freezing resistance is enhanced [25, 29].

Figure 5 shows the variations in mass loss rates of Group A2 specimens (with a water-to-cement ratio of 0.42 ) in testing modes FC and CF. The test results show that, with a water-to-cement ratio of 0.42 , the mass loss rate of the concrete under two cycles is positively correlated with the number of cycles. When the number of cycles is less than 50, the mass loss rate of the concrete in the CF mode is significantly higher than that in the FC mode. When the number of cycles falls between 50 and 75, the effects of the two testing modes work simultaneously. It can be observed that when the effect of one mode increases, the effect of the other decreases. When the number of cycles exceeds 75 , the mass loss rate of the concrete in the FC mode is significantly higher than that in the CF mode, which indicates that freezethaw damage can better inhibit carbonation, rather than reinforce it. Under the effect of freeze-thaw damage, many loose pores and microscopic cracks appear on the surface of the concrete with fly ash as fine congregate, and $\mathrm{CO}_{2}$ reacts with $\mathrm{Ca}(\mathrm{OH})_{2}$ in the concrete to produce $\mathrm{CaCO}_{3}$, which fills in the internal fissures of the concrete [30]. However, the filling effect does not in any way compensate for the influence of freeze-thaw damage on the mass loss rate of the concrete.

3.3. Relative Dynamic Modulus of Elasticity. The relative dynamic modulus of elasticity (RDME) can be used to reflect the development of microcracks in concrete, and variations in the RDME represent the amount of freeze-thaw damage that has affected it [31]. Figure 6 shows the RDMEs of specimens in Groups A1, A2, and A3 for different testing modes. Figure 6(a) shows that the lowest change rate of RDME is $6.8 \%$ with less than 200 cycles at a water-to-cement ratio of 0.36 . In addition, at a water-to-cement ratio of 0.48 and less than 50 cycles, the loss change rate of RDME is only $3.7 \%$, which is insignificant. There is a sharp drop in the RDME when the number of cycles is between 50 and 75, and the maximum loss change rate is $8.4 \%$, and the loss change rate is maintained at nearly constant between 75 and 200 cycles. In general, when the water-cement ratio is greater, the concrete has less resistance to freeze-thaw damage [32]. The RDME of the concrete under both FC (Figure 6(a)) and CF (Figure 6(b)) modes is less than that under the F mode (Figure 6(c)); therefore, the resistance of concrete to freeze- 


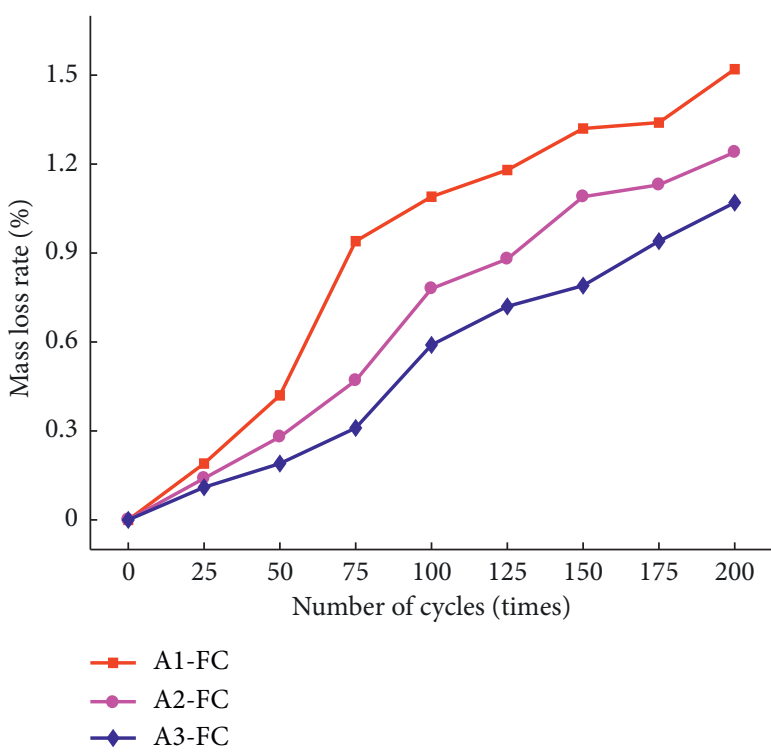

(a)

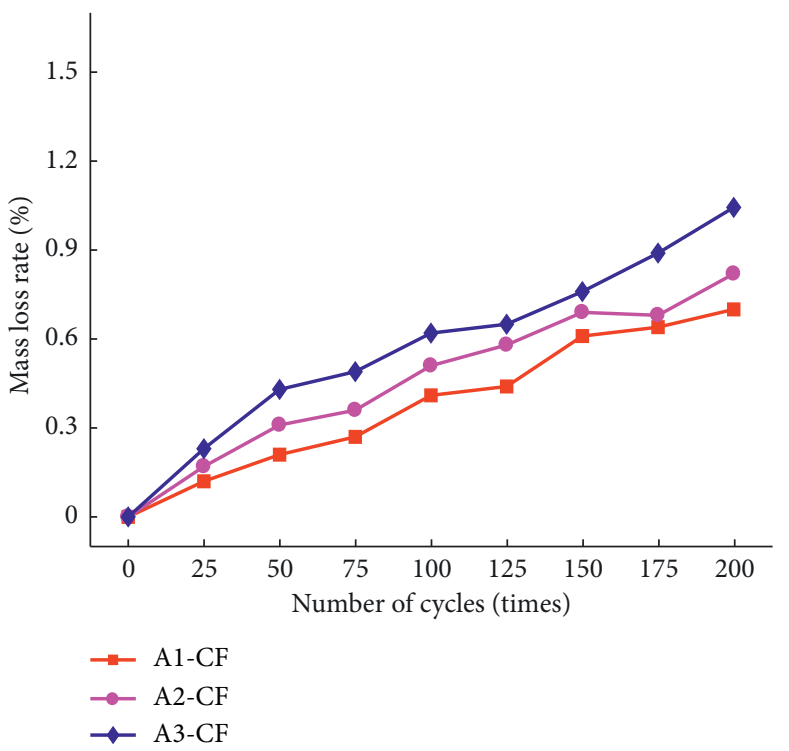

(b)

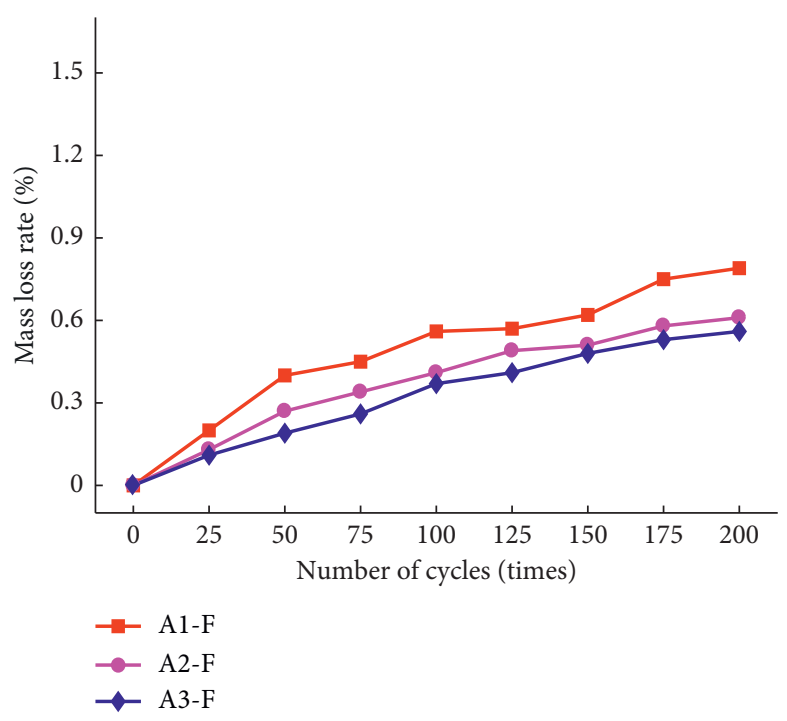

(c)

Figure 4: Mass loss rates of A1, A2, and A3 with different testing modes: (a) FC mode; (b) CF mode; (c) F mode.

thaw cycles under alternative attacks of freeze-thaw and carbonation is lower than that under a single freeze-thaw mode.

Figure 7 shows the variations in RDMEs of Group A2 specimens at FC and CF testing modes. The test results infer that the RDME of the concrete after initial carbonation is higher than that after initial freeze-thaw cycling, and this occurs because of the degree of compactness of its internal structure. In other words, this type of concrete has superior freeze-thaw resistance.

An analysis of Figures 6 and 7 indicates that, under alternative attacks of freeze-thaw and carbonation, the relation between the RDME $\left(E_{d}\right)$ and freeze-thaw cycles $(n)$ of the concrete with fly ash as fine aggregate can be expressed as a function, e.g., $E_{d}=f(n)$, and its first derivative is

$$
f^{\prime}(n)=\frac{d E_{d}}{d n} .
$$

Through a differential equation solution, given the boundary conditions, the evolution equation for the RDME of the concrete under alternative attacks of freeze-thaw and carbonation can be obtained as follows:

$$
E_{d}=a_{1} n^{2}+a_{0} n+1,
$$

where $a_{0}$ and $a_{1}$ represent the parameters relating to concrete with fly ash as fine aggregate.

The RDMEs of A2-FC specimens under alternating freezethaw attacks and carbonation can be obtained using equation (3). Figure 8 shows the fitting curve and coefficients of determination $R^{2}=0.979$, which adequately represents the fitting. 


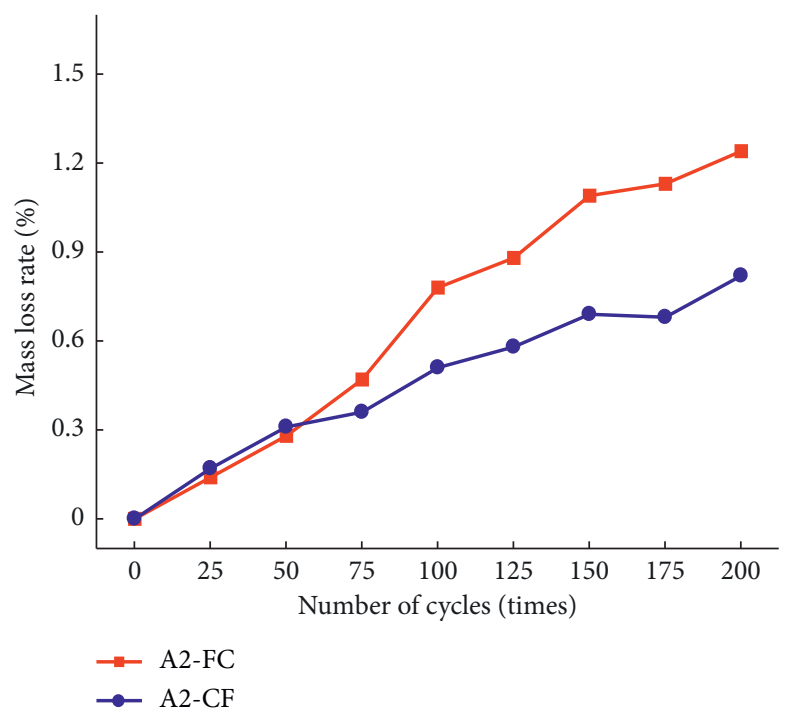

FIgURe 5: Mass loss rate of A2 subjected to alternative cycles of freeze-thaw and carbonation.

3.4. Relative Compressive Strength. Figure 9 presents the results of relative compressive strength (RCS) tests conducted on the concrete for different testing modes (C, F, FC, and CF). Under the $\mathrm{C}$ mode, the RCS of concrete is expressed as the ratio of the compressive strength before carbonation to that after carbonation. The RCS values of the concrete at the modes F, FC, and CF are calculated by the ratio of their compressive strengths after $n$ time of single freeze-thaw or $i$ time of alternating freeze-thaw and carbonation to that obtained before tests were conducted. Note that compressive strength is measured in the tests under standard curing for 56 days.

It is evident from Figure 9(a) that there is an increase in the compressive strength of the concrete in Groups A1, A2, and $\mathrm{A} 3$ in the $\mathrm{C}$ mode when the early carbonation is up to 15 days. This is because, on the one hand, in the process of carbonation, cement hydration products react with $\mathrm{CO}_{2}$ to produce $\mathrm{CaCO}_{3}$, which gradually fills the voids of the aggregate and then enhances the density of the concrete. On the other hand, the active ingredients in fly ash react with $\mathrm{Ca}(\mathrm{OH})_{2}$ to produce calcium silicate hydrate $(\mathrm{CSH})$ and hydrated calcium aluminate gel, which are hardly soluble in water. Thus, concrete becomes more compact with less porosity. As a result, the strength of the concrete with fly ash as fine congregate is improved after carbonation. It is worth pointing out that it leads to the dramatic reduction of compressive strength after 15 days of carbonation, which may be attributed to the cracks caused by the expansion of $\mathrm{CaCO}_{3}$ and ice [33]. However, in the $\mathrm{F}$ mode, there is a significant decrease in the compressive strength with an increase in the number of cycles. Figures 9(b) and 9(c) show that, for different test modes, there is a decrease in the RCS values of the concrete with an increase in the freeze-thaw cycles. The RCS values in FC and CF modes are slightly higher than those in the $\mathrm{F}$ mode, and after the same number of freeze-thaw cycles, the RCS values in the CF mode are higher than those in the FC mode, particularly during the initial stage of the test. The initial carbonation results in a change in the microstructure of hydration products in cement-based materials and causes the formation of calcium carbosilicate hydrates, which are actually a combination of C-S-H gels and some nano-scale $\mathrm{CaCO}_{3}$ crystals [31]. However, from a thermodynamic perspective, these calcium carbosilicate hydrates are more stable than C-S-H gels, and their formation contributes to strength development after initial carbonation [34]. However, with an increase in the number of freeze-thaw cycles, the improvement is reduced gradually.

3.5. Carbonation Depth. To investigate the carbonation resistance of the concrete in a complicated environment, the carbonation depth and velocity coefficient in different test modes are analyzed in this section, as shown in Figures 10 and 11 .

From Figure 10, it can be observed that the carbonation depth of the concrete specimens in three different groups increases gradually with an increase in the carbonation time. In particular, when the water-to-cement ratio is larger, the carbonation depth is deeper. This is because concrete specimens with a larger water-to-cement ratio usually have a greater number of pores, which are more prone to $\mathrm{CO}_{2}$ permeation [35]. The carbonation depth was lower in the A1 specimen with a water-to-cement ratio of 0.36 because of the lower capillary porosity of the specimens. In contrast, the carbonation depth was greater in the A3 specimen with a water-to-cement ratio of 0.48 , even during the initial alternating cycles. With the same length of carbonation time, the carbonation depths of concrete specimens in FC and CF modes were greater than after single carbonation. The carbonation depth of concrete in the FC mode was deeper than that in the CF mode because the initial freeze-thaw cycle produces microcracks in the concrete, which accelerate diffusion of $\mathrm{CO}_{2}$ in the concrete and subsequently boost carbonation. It is also observed that, with a fewer number of alternating cycles, the carbonation depth curves in Figure 10 


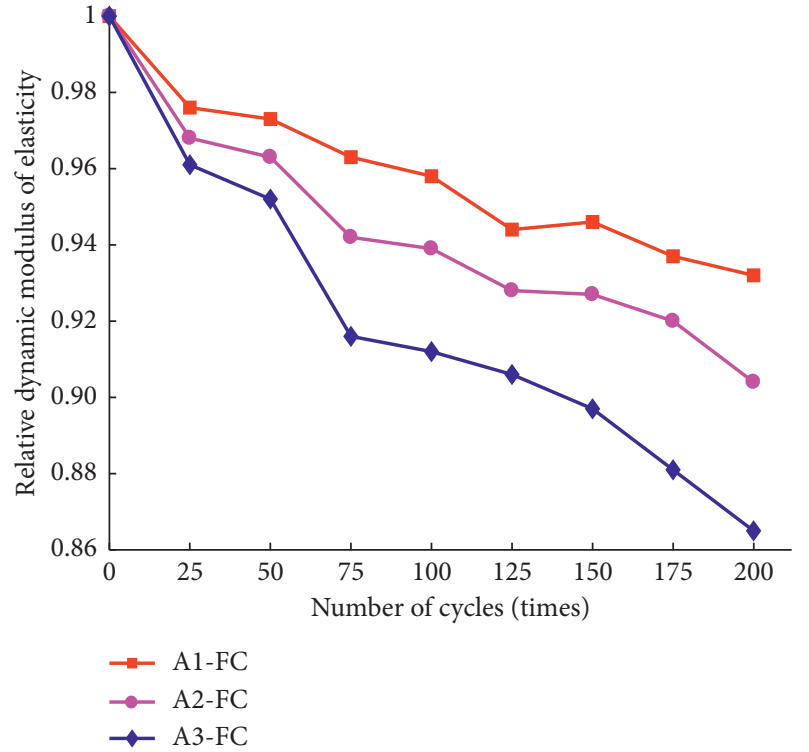

(a)

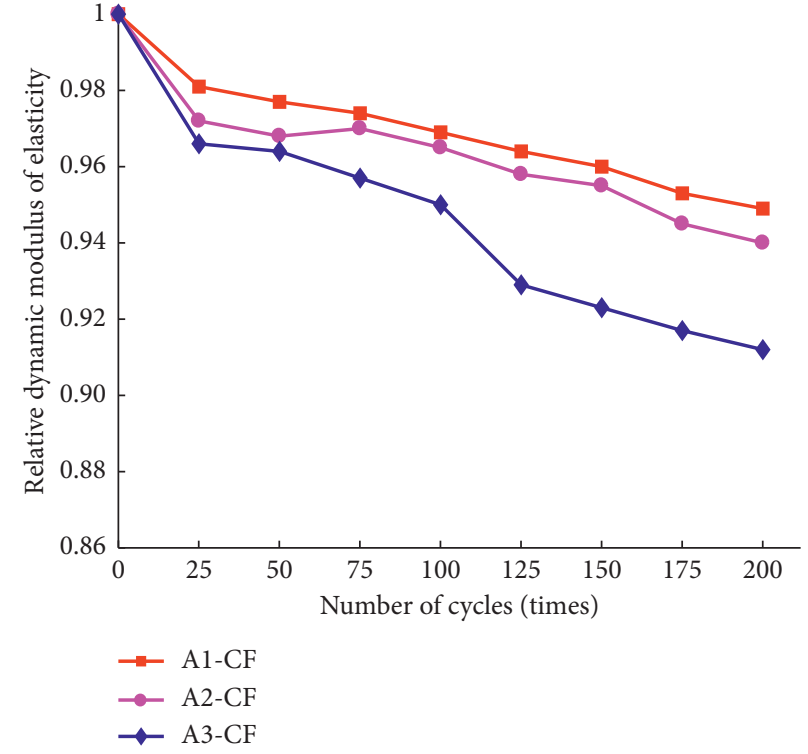

(b)

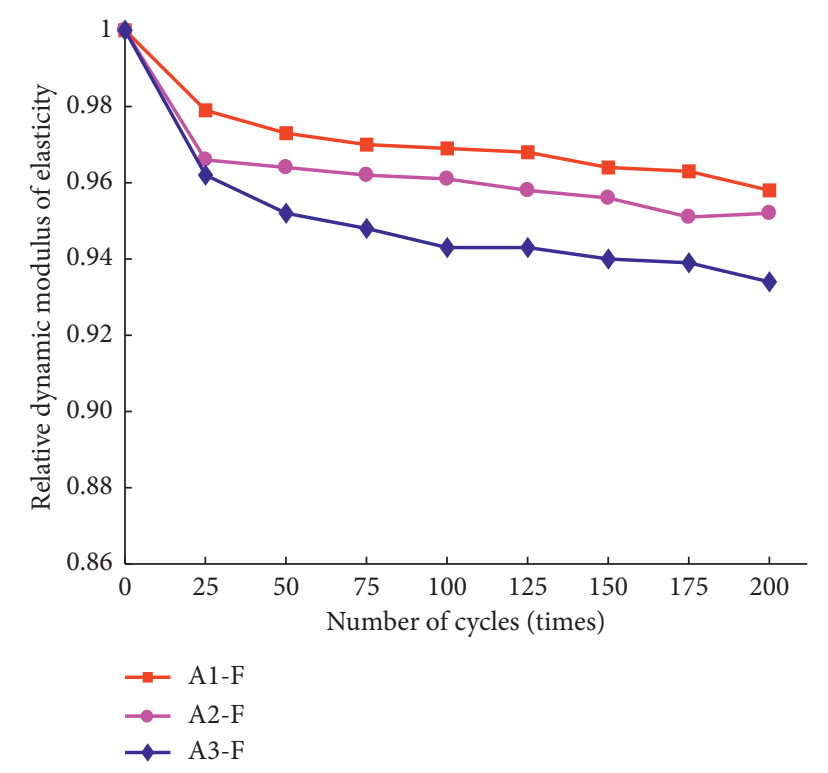

(c)

Figure 6: Relative dynamic modulus of elasticity of A1, A2, and A3 for different testing modes: (a) FC mode; (b) CF mode; (c) F mode.

are gradually reduced with an increase in the number of alternating cycles. This is because the chemical reaction in the initial carbonation process results in a sharp decrease in the alkalinity of the concrete, and the average $\mathrm{pH}$ value drops from 12 or 14 to 8 or 9 . With an increase in calcium hydroxide, the carbonation depth increases [36] but subsequently stabilizes as the amount of calcium hydroxide is reduced.

The current well-established prediction model for the concrete carbonation depth is derived based on Fick's first law of diffusion, and the model function is given as follows [37]:

$$
X_{\mathrm{c}}=K \sqrt{t},
$$

where $X_{\mathrm{c}}$ is the carbonation depth $(\mathrm{mm}), t$ is the carbonation time (day), and $K$ is the carbonation velocity coefficient, $\mathrm{mm} / \sqrt{t}$. By using test data, the carbonation velocity coefficient $K$ of Group A2 specimen can be obtained from equation (4), and this is plotted in Figure 11. It can be seen from Figure 11 that, as the carbonation time increases, the carbonation velocity coefficient of the concrete specimens at the $\mathrm{C}$ mode firstly increases and then decreases after carbonation. In the CF mode, there is a continuous increase in the carbonation velocity coefficient of the concrete specimens. This indicates that, in the $\mathrm{C}$ mode, the surface of concrete specimens is tighter due to the carbonation effect, which hinders and delays subsequent carbonation [38]. In the FC mode, as freeze-thaw aggravates the damage on the concrete's surface, it becomes less compact, which leads to continuous carbonation. 


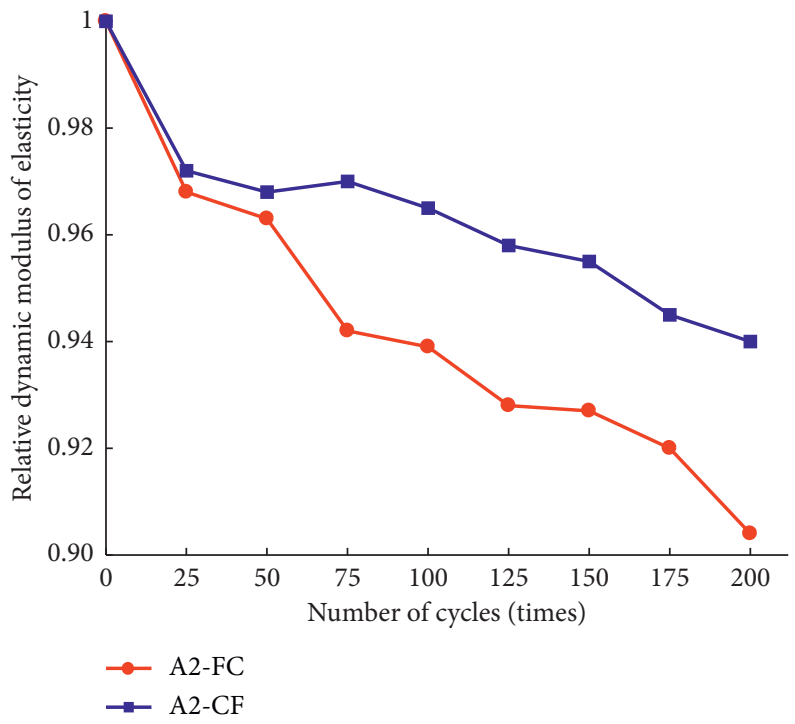

Figure 7: Relative dynamic modulus of elasticity of A2 subjected to alternating freeze-thaw cycles and carbonation.

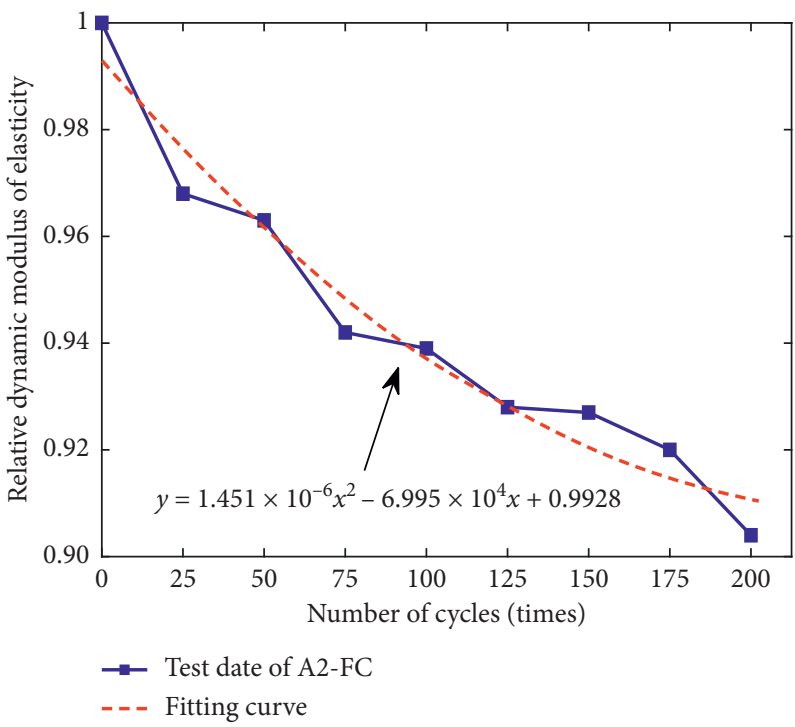

FIGURE 8: Simulation of the evolution equation for concrete relative dynamic modulus of elasticity under alternating freeze-thaw attacks and carbonation.

3.6. Microstructure Analysis. As a heterogeneous porous material, concrete usually contains defects such as microcracks, which make it vulnerable to the effects of freeze-thaw and harmful substances such as $\mathrm{CO}_{2}$ invading its interior [39]. To further analyze the deterioration mechanism of concrete under alternating freeze-thaw and carbonation cycles, microstructure analyses were conducted using the scanning electron microscope (SEM) and X-ray diffraction (XRD) to analyze Group A2 specimens.

3.6.1. Scanning Electron Microscope (SEM). Figure 12 shows the microstructures of Group A2 specimens before the test and after the fourth alternative cycle period. Figure 12(a) shows many microcracks in the interior of undamaged concrete, and a large number of crystalline ettringite (AFt) crystals distributed in the laminar C-S-H gels with a low degree of hydration at cracks. These crystals facilitate the nucleation of $\mathrm{CaCO}_{3}$. In addition, the carbonation reaction rate is relatively higher in these crystals than in other segments. When carbonation progresses to 20 days (Figure 12(b)), the product of the reaction between C-S-H gels and $\mathrm{CO}_{2}, \mathrm{CaCO}_{3}$, fills internal pores and microcracks and is deposited on the surface of pores [40-43]. This causes the pores to shrink, and the porosity rate of the concrete decreases, but its compactness increases [44]; therefore, the mechanical property of specimens is enhanced after carbonation. When the number of freeze-thaw cycles reaches 200 , a number of cracks are clearly observed in the concrete (Figures 12(c) and 12(d)); these are evenly distributed on the 


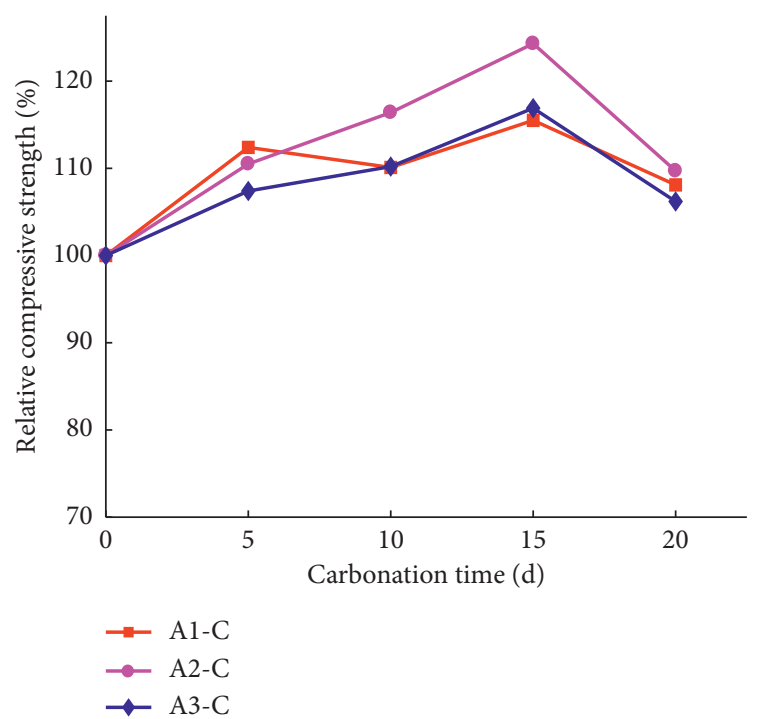

(a)

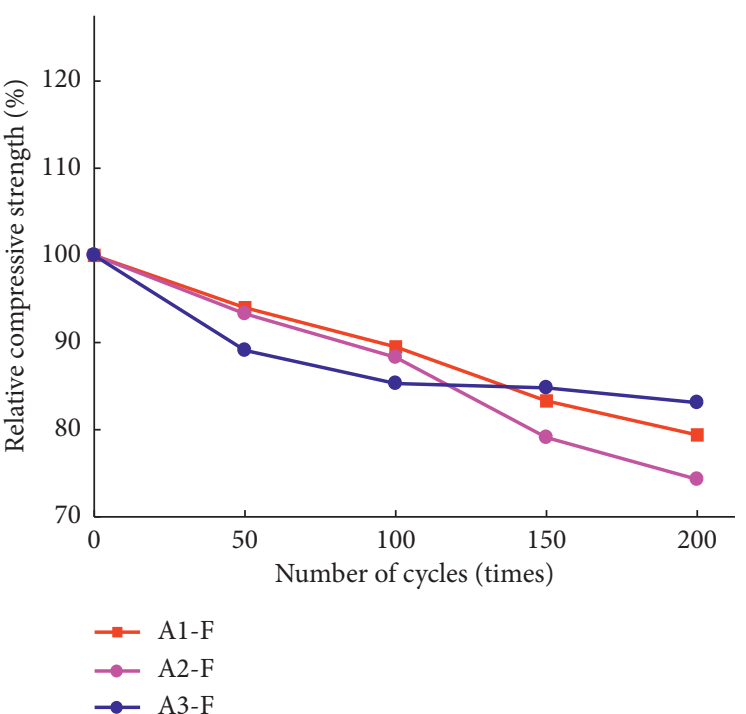

(b)

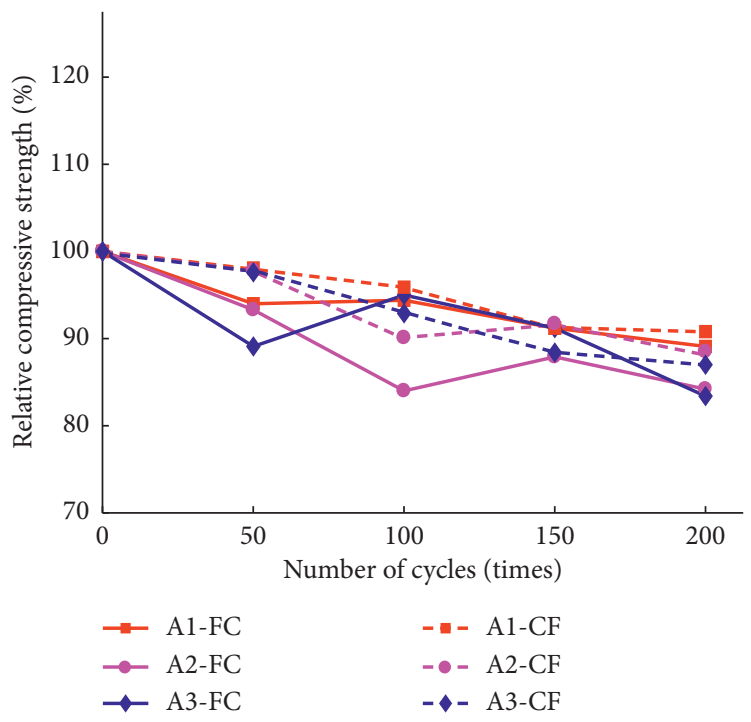

(c)

Figure 9: Relative compressive strengths of A1, A2, and A3 with different testing modes: (a) C mode; (b) F mode; (c) FC and CF modes.

surface but do not intersect each other. The cement pastes and aggregates constitute an integral structure through nestification. The space between hydration products is very close, while the spaces around microcracks are flocculent with high density. This indicates that both the icing and osmotic pressures caused by freeze-thaw cause cracks in the concrete [23], and these cracks continue to grow and extend outwards with an increase in the number of freeze-thaw cycles, until the specimen is destroyed. Figures 12(d)-12(f) clearly show cracks in the concrete surface in all three modes. With the CF mode, cracks arise in the transition area of the concrete-aggregate boundary but do not intersect. The nestification structure is partly disturbed, the space between hydration products becomes relatively loose and flocculent, and many hydration products peel off from the cement matrix. With the FC mode, the concrete shows greater damage: microcracks are intensively distributed in the transition area of concrete-aggregate boundary and are mutually intersected. When the nestification structure is damaged, the width and depth of microcracks in the transition area of concrete-aggregate boundary increase significantly. The space between hydration products becomes greater, making them look flocculent. The microcracks at the concrete surface appear like gullies, and the cement matrix in the intersection of cracks falls off seriously.

3.6.2. X-Ray Diffraction (XRD). Figure 13 shows the X-ray diffraction (XRD) patterns of the concrete in the A2 group before and during the fourth alternative cycle. Carbonation alone causes chemical alteration, where the new main hydration product in the concrete is calcite formed from the 


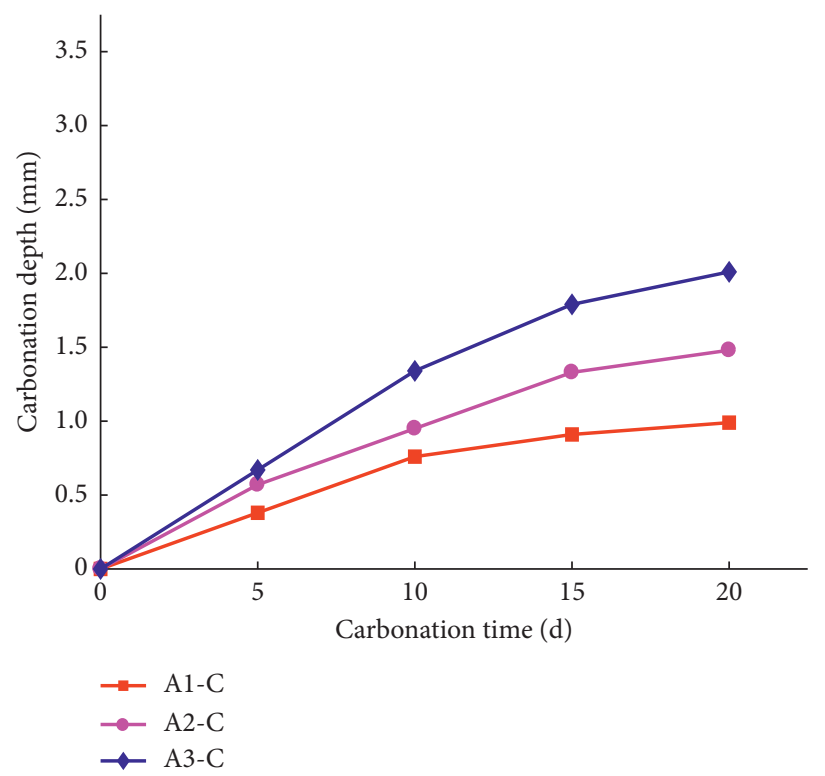

(a)

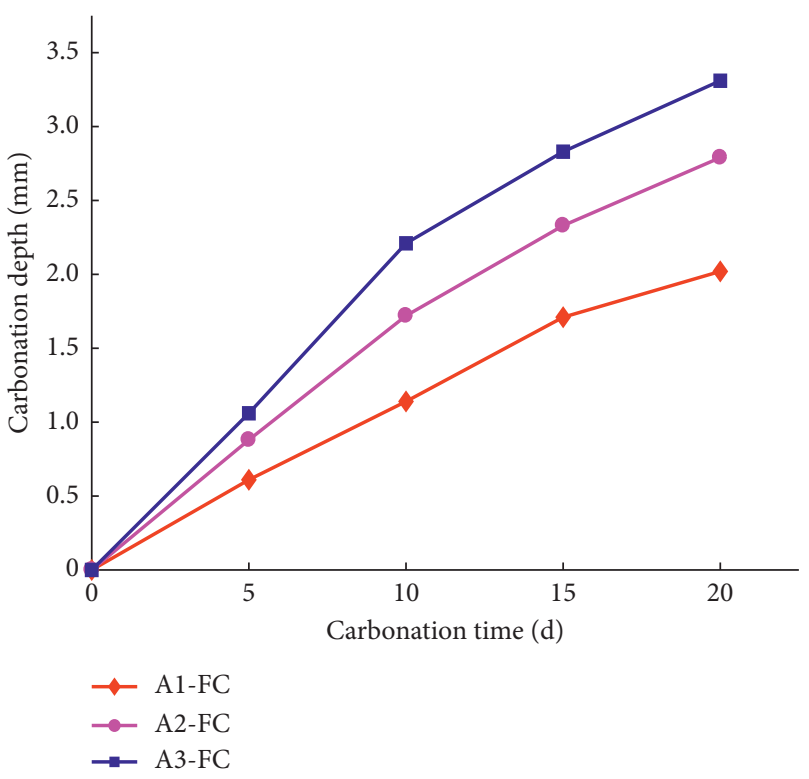

(b)

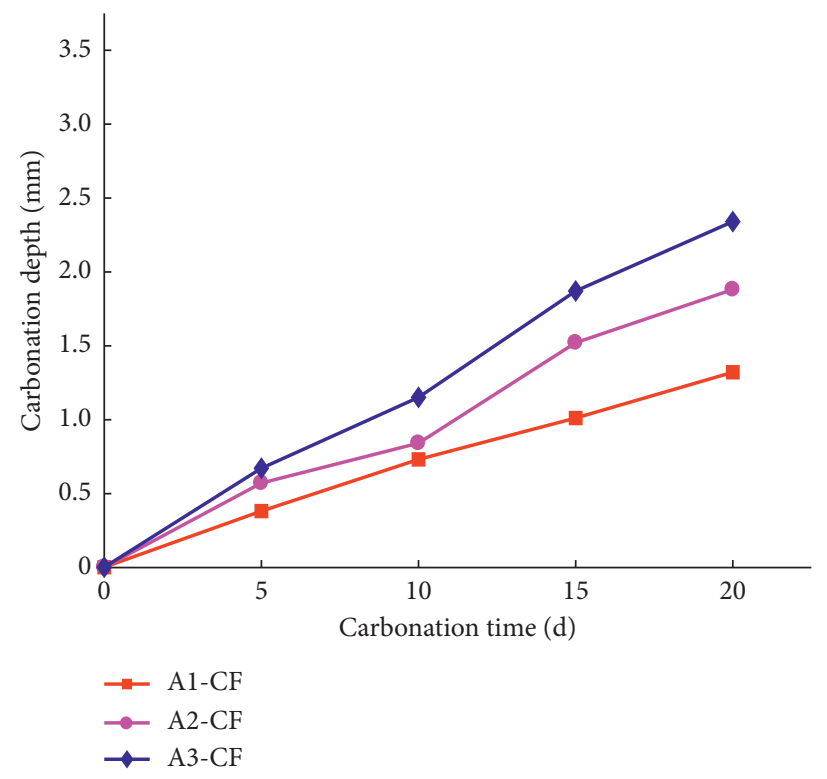

(c)

Figure 10: Carbonation depth of A1, A2, and A3 in different testing modes: (a) C mode; (b) FC mode; (c) CF mode.

consumption of portlandite, whereas the single freeze-thaw attack causes physical alteration, but any new compounds are formed [31]. The freeze-thaw cycle generally affects the external layer and extends internally only when the temperature drops further. Surface cracks associated with an increase in internal deterioration due to freeze-thaw attacks facilitate $\mathrm{CO}_{2}$ penetration, and it is well known that $\mathrm{CO}_{2}$ penetrates into the interior from the concrete surface; this indicates that the calcite is usually deposited on the surface, and relatively less amount is found inside.

\subsection{Analysis of Alternative Freeze-Thaw and Carbonation} Mechanisms. Two alteration processes affect the deterioration mechanism of concrete with fly ash as fine aggregate from freeze-thaw and carbonation, where the former is a physical change and the latter is a complicated chemical change. In the FC mode, freeze-thaw cycling causes the structure of concrete to gradually change from one that is compact to the one that is loose and porous. In the process of rapid carbonation, a neutral reaction occurs between highpermeability $\mathrm{CO}_{2}$ and $\mathrm{Ca}(\mathrm{OH})_{2}$ in the concrete, which produces $\mathrm{CaCO}_{3}$ that fills the interior pores. The $\mathrm{CaCO}_{3}$ works as a grouting material, and temporarily reduces the porosity of the concrete [45]. According to the principle of kinetics in a chemical reaction, as the reactant (such as the cementing material $\mathrm{Ca}(\mathrm{OH})_{2}$ ) is continuously consumed, there is a rapid decrease in the reaction concentration, which results in a reaction equilibrium short of internal impetus 


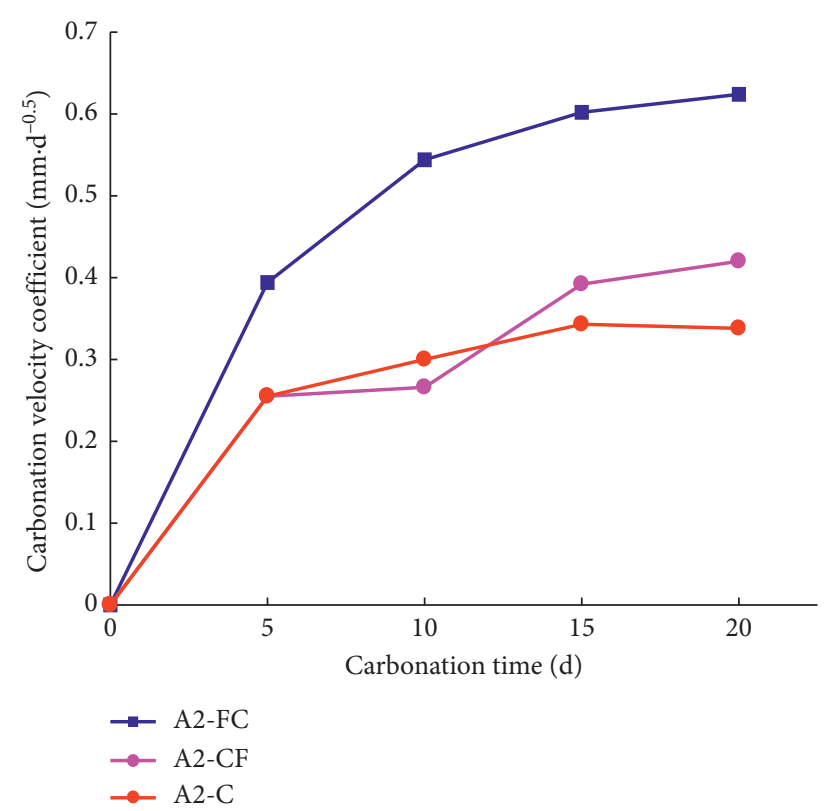

FIGURE 11: Carbonation velocity coefficient of A2 in different testing modes.

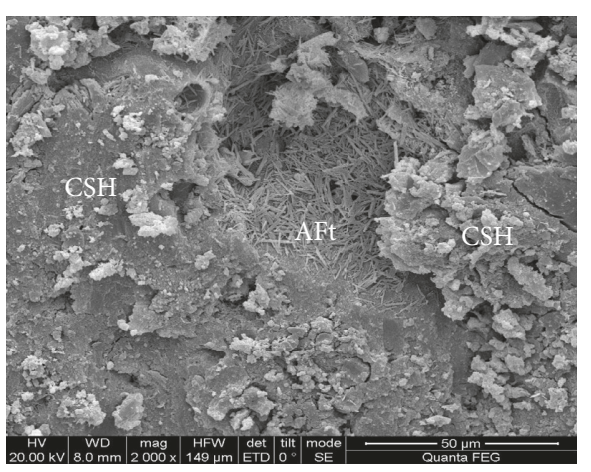

(a)

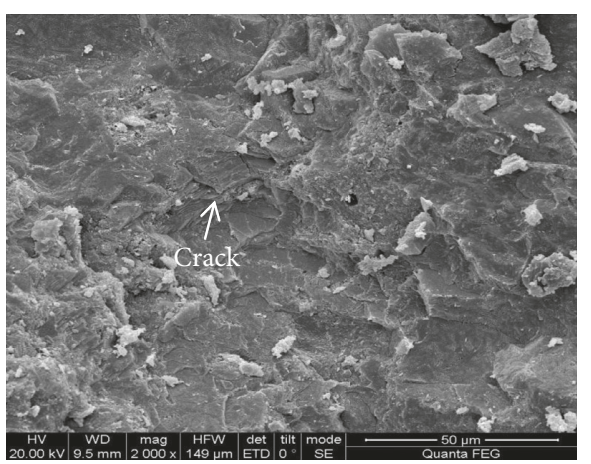

(c)

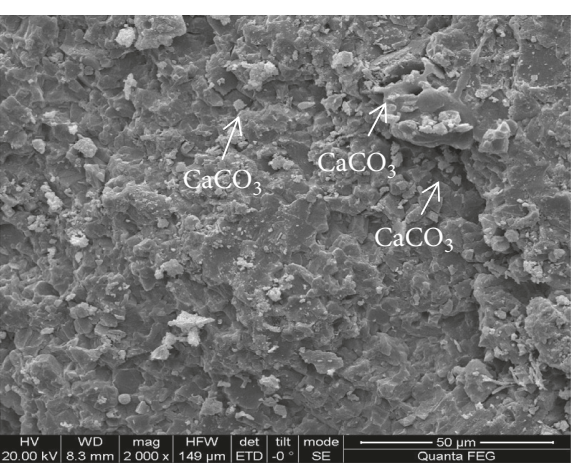

(b)

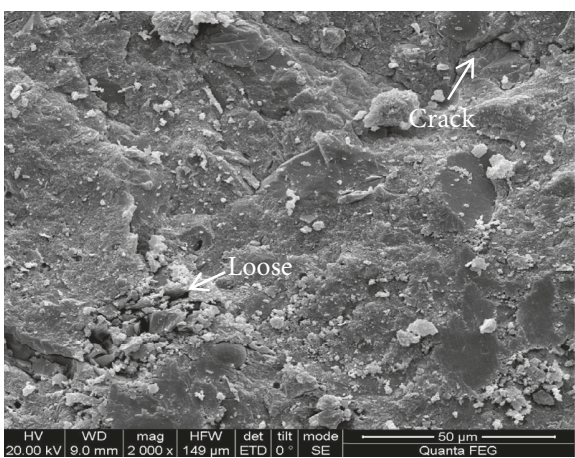

(d)

Figure 12: Continued. 


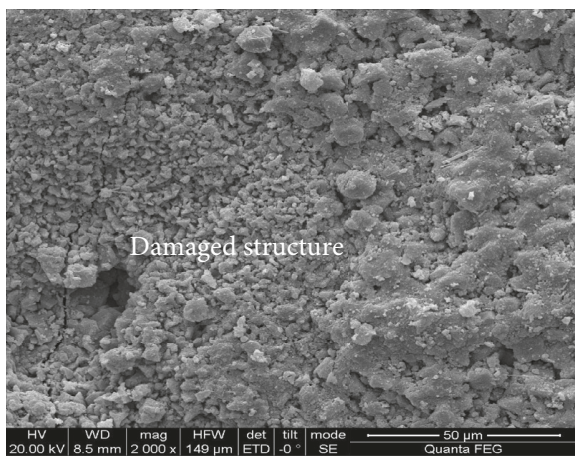

(e)

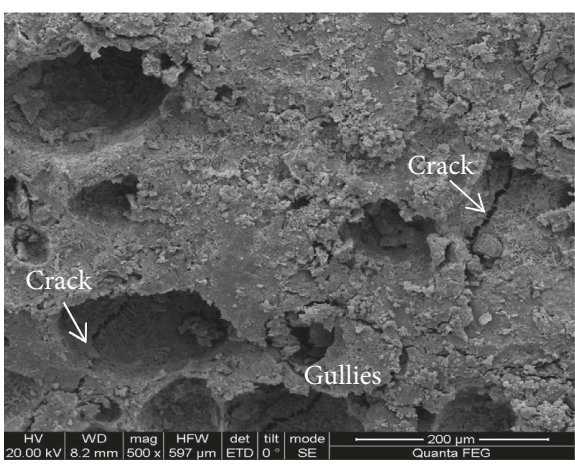

(f)

Figure 12: SEM of Group A2 samples before test and after the fourth alternating cycle period: (a) A2; (b) A2-C; (c) A2-F; (d) A2-CF; (e) A2-FC; (f) A2-FC.

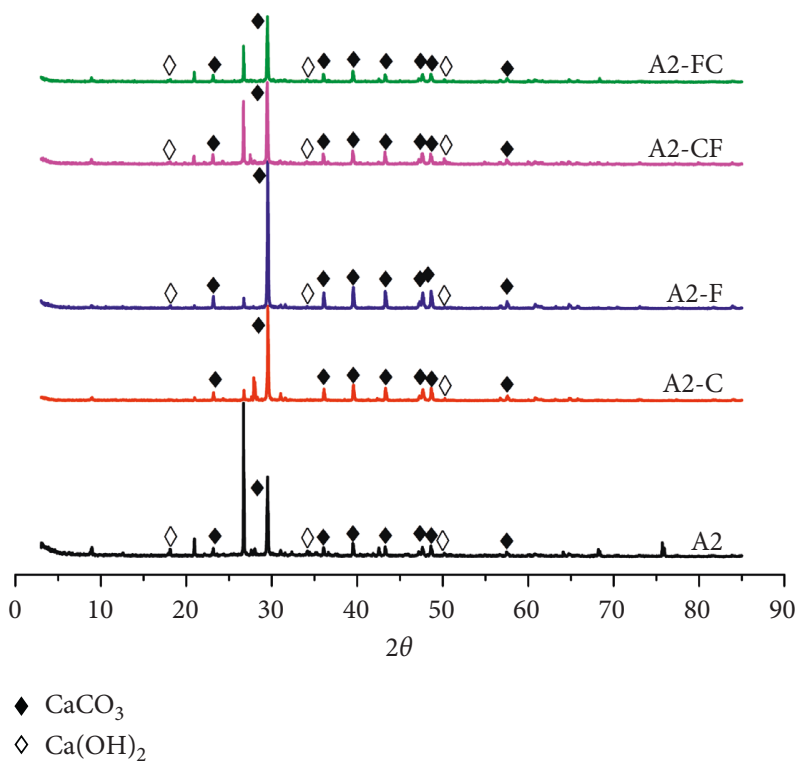

FIGURE 13: XRD analysis of A2 interior.

[46-49]. In addition, new pores are developed in the concrete so that its freeze-thaw resistance is lowered with an increase in freeze-thaw cycles. This also verifies that the concrete strength increases due to the carbonation in the early test stages, but it decreases sharply with an increase in the number of alternating cycling tests. The opposite occurs with respect to the deterioration mechanism of the concrete with fly ash as fine aggregate in the CF mode. An analysis of the deterioration mechanism under alternating actions shows that the mass loss rate, RDME, and carbonation depth of the concrete in the CF mode are all significantly higher than those in the FC mode.

\section{Conclusions}

This study analyzed the durability of concrete with fly ash as fine aggregate under alternating attacks of freeze-thaw and carbonation, and the following conclusions can be drawn:
(1) The durability of the concrete with fly ash as fine aggregate under alternative freeze-thaw cycles and carbonation is very different from that relating to single freeze-thaw and single carbonation. Carbonation is beneficial for refining the pore structure and increasing the strength in the initial alternating cycle, which makes the concrete compact and reduces its capillary pores, thus delaying freeze-thaw damage. The concrete cracks resulting from the freeze-thaw cycles cause crack propagation, which leads to an intensification of carbonation.

(2) The mass loss rate and relative dynamic modulus of elasticity under alternative freeze-thaw actions and carbonation are positively correlated with the cycle number and the water-to-cement ratio. The frost resistance of concrete in both FC and CF modes is inferior to that in the $\mathrm{F}$ mode, and a damage prediction model with the higher accuracy can be established for the FC mode. 
(3) The carbonation coefficient of concrete specimens firstly increases and then reduces under single carbonation. The freeze-thaw environment is a catalyst for accelerating carbonation corrosion of the concrete with fly ash as fine aggregate, and this aggravates surface damage and causes the concrete surface to lose density. As a result, the carbonation coefficient of concrete with fly ash as fine aggregate continues to increase under alternating freeze-thaw and carbonation.

(4) As observed from the microstructure analysis, the continuous consumption of the reactant (such as the cementing material $\mathrm{Ca}(\mathrm{OH})_{2}$ ) results in a reaction equilibrium short of internal impetus. In addition, with the expansion of crystalline ice and $\mathrm{CaCO}_{3}$, a large number of new cracks are formed during new alternative cycles.

\section{Data Availability}

The data used to support the findings of this study are available from the corresponding author upon request.

\section{Conflicts of Interest}

The authors declare that they have no conflicts of interest.

\section{Acknowledgments}

This study was supported by the National Natural Science Foundation of China (51568055) and the Special Projects for Scientific and Technological Cooperation with Foreign Countries of Ningxia Province of China (2018BFH03002). Their results were fundamental to this study.

\section{References}

[1] T. Bilir, O. Gencel, and I. B. Topcu, "Properties of mortars with fly ash as fine aggregate," Construction and Building Materials, vol. 93, pp. 782-789, 2015.

[2] H. Ş. Arel and F. U. A. Shaikh, "Effects of fly ash fineness, nano silica, and curing types on mechanical and durability properties of fly ash mortars," Structural Concrete, vol. 19, no. 2, pp. 597-607, 2018.

[3] G. Xun, Y. Hong, Z. Dan et al., "Leaching characteristics of heavy metals in fly ash from a Chinese coal-fired power plant," Asia-Pacific Journal of Chemical Engineering, vol. 5, no. 2, pp. 330-336, 2010.

[4] A. M. Rashad, "An exploratory study on high-volume fly ash concrete incorporating silica fume subjected to thermal loads," Journal of Cleaner Production, vol. 87, no. 1, pp. 735-744, 2015.

[5] F. U. A. Shaikh and S. W. M. Supit, "Compressive strength and durability properties of high volume fly ash (HVFA) concretes containing ultrafine fly ash (UFFA)," Construction and Building Materials, vol. 82, pp. 192-205, 2015.

[6] T. Seo, M. Lee, C. Choi, and Y. Ohno, "Properties of drying shrinkage cracking of concrete containing fly ash as partial replacement of fine aggregate," Magazine of Concrete Research, vol. 62, no. 6, pp. 427-433, 2010.
[7] H. Mihashi, "Characteristic points of AIJ recommendations for practice of crack control in reinforced concrete buildings (design and construction)," Concrete Journal, vol. 45, no. 2, pp. 9-15, 2007.

[8] S. C. K. Bendapudi and P. Saha, "Contribution of fly ash to the properties of mortar and concrete," International Journal of Earth Sciences and Engineering, vol. 4, no. 6, pp. 10171023, 2011.

[9] L. J. Malvar and L. R. Lenke, "Efficiency of fly ash in mitigating alkali-silica reaction based on chemical composition," ACI Materials Journal, vol. 103, no. 5, p. 319, 2006.

[10] M. H. Kim, Y. J. Kwon, S. J. Choi, S. P. Kang, and J. H. Shim, "A study on the properties of high volume fly-ash concrete according to the replacement method and ratio of fly-ash," Journal of the Architectural Institute of Korea Structure \& Construction, vol. 18, no. 2, pp. 123-130, 2002.

[11] H. Kitayama, T. Koyama, H. Koyamada, H. Suyama, and Y. Matufuji, "Compressive strength of recycled aggregate concrete by containing fly ash with constant cement content," in Proceedings of the Summaries of Technical Papers of the Annual Meeting of the Architectural Insti-tute of Japan, vol. A1-1, pp. 699-700, 2006, in Japan.

[12] K. Sakai, T. Koyama, H. Koyamada, H. Suyama, K. Ito, and Y. Matufuji, "Study on strength of concte containing large quantities of inorganic powder with constant cement content," in Proceedings of the Summaries of Technical Papers of the Annual Meeting of the Architectural Insti-tute of Japan, vol. A1-1, pp. 350-351, 2007, in Japan.

[13] K. Ishimaru, H. Mizuguchi, C. Hashimoto, T. Ueda, K. Fujita, and M. Ohmi, "Properties of concrete using copper slag and second class fly ash as a part of fine aggregate," Journal of the Society of Materials Science, Japan, vol. 54, no. 8, pp. 828-833, 2005.

[14] M. Ferreira, H. Kuosa, M. Leivo, and E. Holt, "Concrete performance subject to coupled deterioration in cold environments," Nuclear Engineering and Design, vol. 323, pp. 228-234, 2016.

[15] H. Kuosa, R. M. Ferreira, E. Holt, M. Leivo, E. Vesikari, and C. Composites, "Effect of coupled deterioration by freeze-thaw, carbonation and chlorides on concrete service life," Cement and Concrete Composites, vol. 47, pp. 32-40, 2014.

[16] GB/T 50146-2014, National Standard of the People's Republic of China, Technical Code for Application of Fly Ash Concrete, National Standard of the People's Republic of China, Beijing, China, 2014, in Chinese.

[17] China Meteorological Administration, Historical Data Query, China Meteorological Administration, Beijing, China, 1997, in Chinese, http://www.cma.gov.cn/2011qxfw/2011qsjcx/.

[18] Y. Yin and Z. Li, "Discussion on freeze-thaw cycles of concrete in representative cities of China," Low Temperature Architecture Technology, vol. 37, no. 11, pp. 12-15, 2015.

[19] GB/T 50082-2009, National Standard of the People's Republic of China, Standard for Methods of Long-Term Performance and Durability of Ordinary Concrete, National Standard of the People's Republic of China, Beijing, China, 2009, in Chinese.

[20] M. Alkaysi, S. El-Tawil, Z. Liu, and W. Hansen, "Effects of silica powder and cement type on durability of ultra high performance concrete (UHPC)," Cement and Concrete Composites, vol. 66, pp. 47-56, 2016.

[21] M. J. Setzer, P. Heine, S. Kasparek et al., "Test methods of frost resistance of concrete: CIF-test: capillary suction, internal damage and freeze thaw test-reference method and alternative methods A and B," Materials and Structures, vol. 37, no. 10, pp. 743-753, 2004. 
[22] GB/T 50081-2002, National Standard of the People's Republic of China, Standard for Test Method of Mechanical Properties on Ordinary Concrete, National Standard of the People's Republic of China, Beijing, China, 2002, in Chinese.

[23] T. C. Powers and R. A. Helmuth, "Theory of volume changes in hardened Portland cement pastes during freezing," in Proceedings of the Highway Research Board Annual Meeting, pp. 285-297, Highway Research Board, Washington, DC, USA, 1953.

[24] I. Janotka and T. Nürnbergerová, "Effect of temperature on structural quality of the cement paste and high-strength concrete with silica fume," Nuclear Engineering and Design, vol. 235, no. 17-19, pp. 2019-2032, 2005.

[25] S. C. Paul, B. Panda, Y. Huang, A. Garg, and X. Peng, "An empirical model design for evaluation and estimation of carbonation depth in concrete," Measurement, vol. 124, pp. 205-210, 2018.

[26] S. W. Tang, X. H. Cai, Z. He, H. Y. Shao, Z. J. Li, and E. Chen, "Hydration process of fly ash blended cement pastes by impedance measurement," Construction and Building Materials, vol. 113, pp. 939-950, 2016.

[27] A. Shen, S. Lin, Y. Guo, T. He, and Z. Lyu, "Relationship between flexural strength and pore structure of pavement concrete under fatigue loads and freeze-thaw interaction in seasonal frozen regions," Construction and Building Materials, vol. 174, pp. 684-692, 2018.

[28] C. Yun-Hong, C. Dong-Hua, and W. Yuan, "Relationship between cement content and frost resistance of concrete," Journal of Building Materials, vol. 14, no. 4, pp. 536-531, 2011.

[29] F. U. A. Shaikh and S. W. M. Supit, "Mechanical and durability properties of high volume fly ash (HVFA) concrete containing calcium carbonate $\left(\mathrm{CaCO}_{3}\right)$ nanoparticles," Construction and Building Materials, vol. 70, pp. 309-321, 2014.

[30] Z. Feng, M. O. Liwu, D. Min, and C. Yuebo, "Effect of carbonation curing on mechanical strength and microstructure of mortars prepared with steel slag-cement-mgo-cao blends," Journal of Building Materials, vol. 20, no. 6, pp. 854-861, 2017.

[31] Z. Li, Advanced Concrete Technology, John Wiley \& Sons, Hoboken, NJ, USA, 2011.

[32] S. T. Yildirim, C. Meyer, and S. Herfellner, "Effects of internal curing on the strength, drying shrinkage and freeze-thaw resistance of concrete containing recycled concrete aggregates," Construction and Building Materials, vol. 91, pp. 288-296, 2015.

[33] Z. Liu and W. Hansen, "Freezing characteristics of airentrained concrete in the presence of deicing salt," Cement and Concrete Research, vol. 74, pp. 10-18, 2015.

[34] H. Yang, z. He, and Y. Shao, "Early carbonation behavior of high-volume dolomite powder-cement based materials," Journal of Wuhan University of Technology-Mater. Sci. Ed., vol. 30, no. 3, pp. 541-549, 2015.

[35] S. W. Tang, X. H. Cai, W. Zhou et al., "In-situ and continuous monitoring of pore evolution of calcium sulfoaluminate cement at early age by electrical impedance measurement," Construction and Building Materials, vol. 117, pp. 8-19, 2016.

[36] V. B. Duong, R. Sahamitmongkol, and S. Tangtermsirikul, "Effect of leaching on carbonation resistance and steel corrosion of cement-based materials," Construction and Building Materials, vol. 40, no. 7, pp. 1066-1075, 2013.

[37] P. F. Marques, C. Chastre, and Â. Nunes, "Carbonation service life modelling of RC structures for concrete with Portland and blended cements," Cement and Concrete Composites, vol. 37, no. 3, pp. 171-184, 2013.
[38] J. Ran, J. Zhang, M. Yang, and J. Wang, "Compressive strength of concrete exposed to alternate carbonation and freezing-thawing cycles," Journal of Building Materials, vol. 20, no. 4, pp. 517-521, 2017.

[39] N. Xueli, W. Chaojie, L. Jinxin et al., "Influence of the freezethaw cycle and chlorine salt erosion coupling conditions on frost-resistance of polymer-modified rapid hardening concrete," Materials Review, vol. 31, no. 12, pp. 177-181, 2017.

[40] D. Cui, N. Banthia, Q. Wang, and W. Sun, "Investigation on porosity of partly carbonated paste specimens blended with fly ash through dual CT scans," Construction and Building Materials, vol. 196, pp. 692-702, 2019.

[41] F. Liu, Z. You, X. Yang, and H. Wang, "Macro-micro degradation process of fly ash concrete under alternation of freezethaw cycles subjected to sulfate and carbonation," Construction and Building Materials, vol. 181, pp. 369-380, 2018.

[42] H. Huang, R. Guo, T. Wang et al., "Carbonation curing for wollastonite-Portland cementitious materials: $\mathrm{CO}_{2}$ sequestration potential and feasibility assessment," Journal of Cleaner Production, vol. 211, pp. 830-841, 2019.

[43] B. Šavija and M. Luković, "Carbonation of cement paste: understanding, challenges, and opportunities," Construction and Building Materials, vol. 117, pp. 285-301, 2016.

[44] A. E. M. A. Elmoaty, "Four-years carbonation and chloride induced steel corrosion of sulfate-contaminated aggregates concrete," Construction and Building Materials, vol. 163, pp. 539-556, 2018.

[45] Ö. Cizer, K. Van Balen, J. Elsen, and D. Van Gemert, "Realtime investigation of reaction rate and mineral phase modifications of lime carbonation," Construction and Building Materials, vol. 35, pp. 741-751, 2012.

[46] M. Thiery, G. Villain, P. Dangla, and G. Platret, "Investigation of the carbonation front shape on cementitious materials: effects of the chemical kinetics," Cement and Concrete Research, vol. 37, no. 7, pp. 1047-1058, 2007.

[47] I. Galan, F. P. Glasser, D. Baza, and C. Andrade, "Assessment of the protective effect of carbonation on portlandite crystals," Cement and Concrete Research, vol. 74, pp. 68-77, 2015.

[48] I. G. Richardson, G. W. Groves, A. R. Brough, and C. M. Dobson, "The carbonation of OPC and OPC/silica fume hardened cement pastes in air under conditions of fixed humidity," Advances in Cement Research, vol. 5, no. 18, pp. 81-86, 1993.

[49] A. Hidalgo, C. Domingo, C. Garcia, S. Petit, C. Andrade, and C. Alonso, "Microstructural changes induced in Portland cement-based materials due to natural and supercritical carbonation," Journal of Materials Science, vol. 43, no. 9, pp. 3101-3111, 2008. 


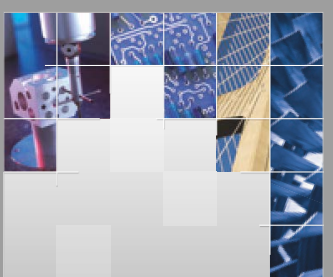

\section{Enfincering}
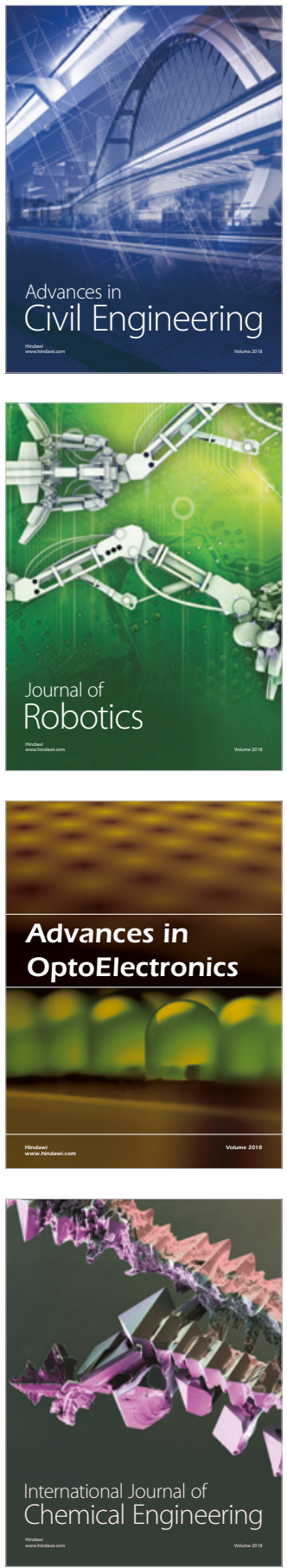

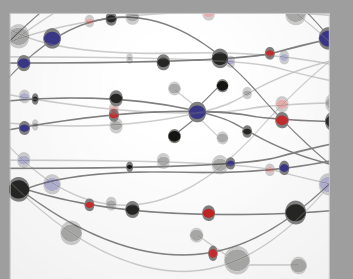

\section{Rotating \\ Machinery}

The Scientific World Journal

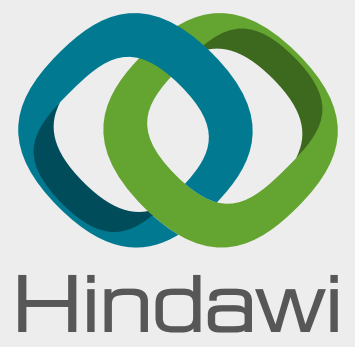

Submit your manuscripts at

www.hindawi.com
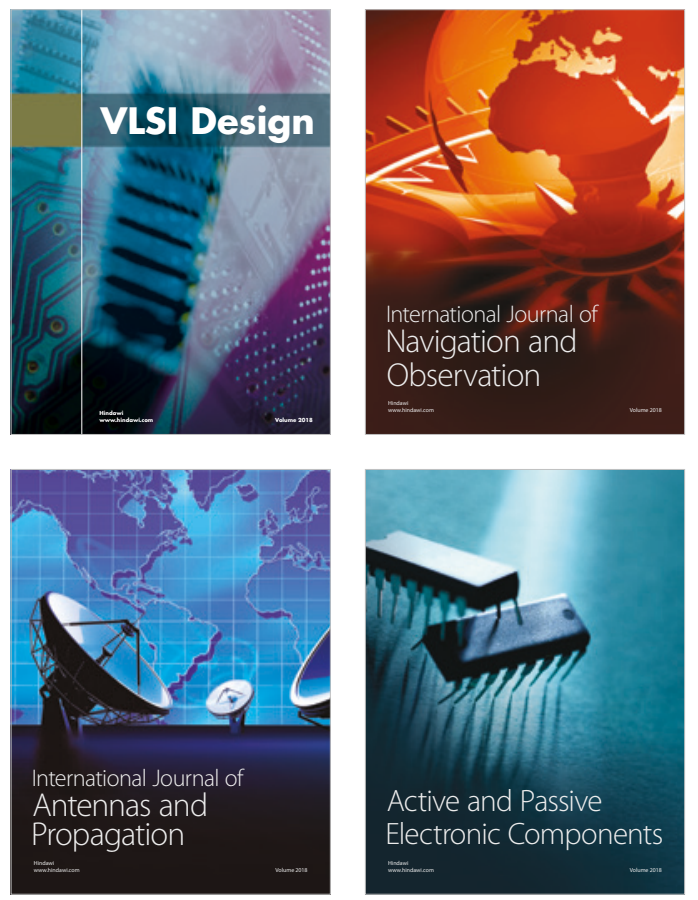
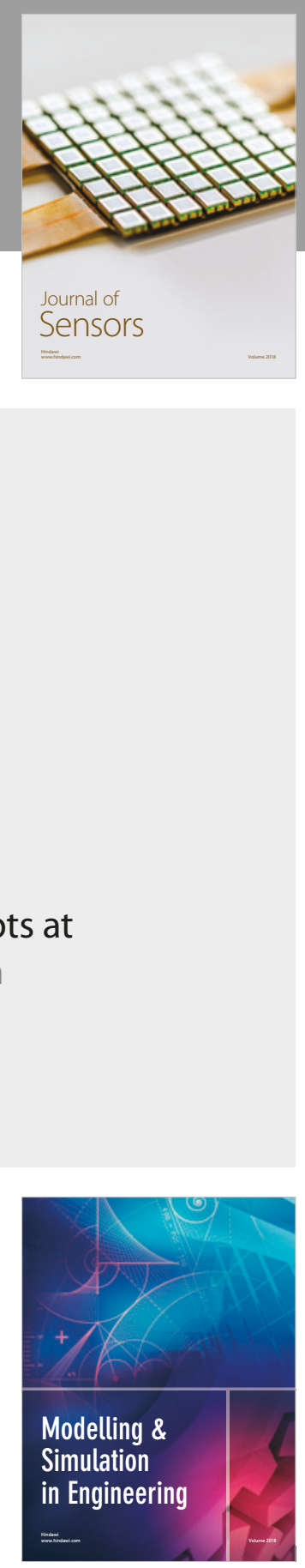

\section{Advances \\ Multimedia}
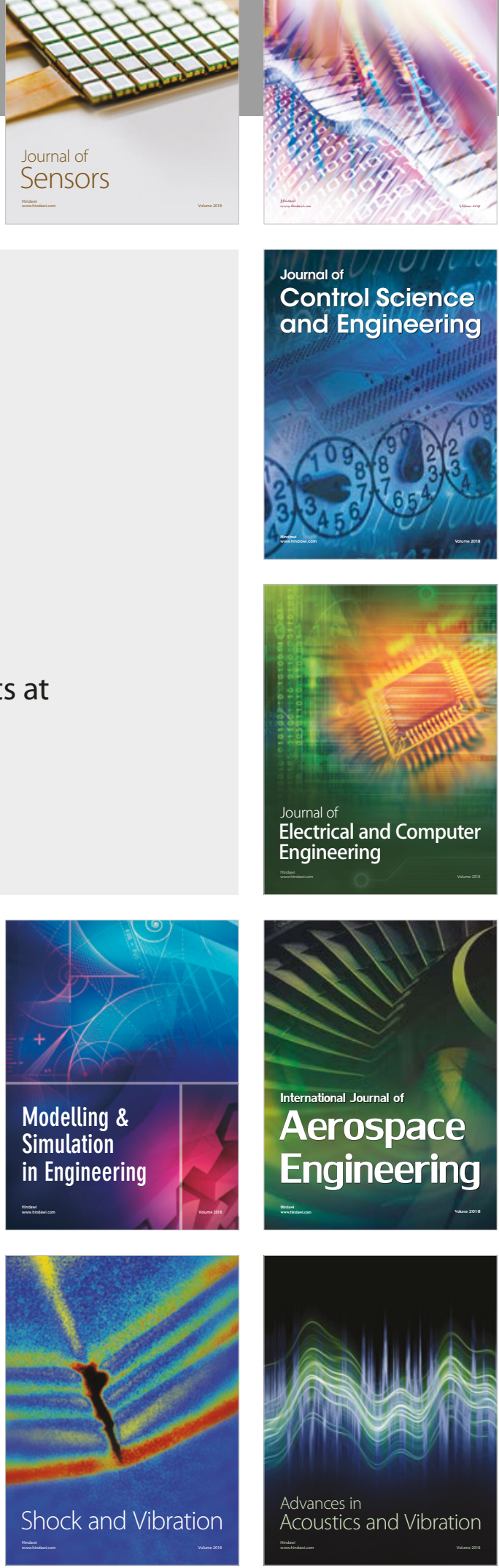